LETTER TO JMG

\title{
Evaluation of widely used models for predicting BRCA 1 and BRCA2 mutations
}

\author{
F Marroni, P Aretini, E D'Andrea, M A Caligo, L Cortesi, A Viel, E Ricevuto, M Montagna, \\ G Cipollini, S Ferrari, M Santarosa, R Bisegna, J E Bailey-Wilson, G Bevilacqua, G Parmigiani, \\ S Presciuttini
}

J Med Genet 2004;41:278-285. doi: 10.1136/jmg.2003.013623

$\mathrm{D}$ eleterious mutations of the $B R C A 1$ and $B R C A 2$ genes are a major risk factor for the development of breast and ovarian cancers. ${ }^{1-4}$ Mutation tests for these two genes commonly are now offered in specialised clinics. ${ }^{56}$ As a result, a large number of women with personal or family histories of breast or ovarian cancer seek genetic counselling. Accurate evaluation of the probability that a woman carries a germline pathogenic mutation at BRCA1 or BRCA2 therefore is essential to help counsellors and those being counselled to decide whether testing is appropriate. In this context, the questions of practical interest are: Given the pedigree, what is the chance of a mutation being present? and What is the chance of the DNA laboratory finding a mutation?

After testing became available, several models were developed to assess the pre-test probability of identifying carriers of mutations. Broadly speaking, two different approaches have been used to develop predictive models: the "empirical approach" and the "Mendelian approach". ${ }^{7}$ In empirical models, families are stratified according to variables that describe their family history; regression or other approaches are used to predict the results of Mendelian testing. In some cases, this approach simply consists of observing the proportion of mutations found in different strata. Mendelian models, in contrast, address the probability that a proband is a mutation carrier on the basis of explicit assumptions about the genetic parameters (allele frequencies and cancer penetrances in carriers and non-carriers) and the Mendelian rules of gene transmission. A consequence of the two different strategies is that the Mendelian models evaluate the probability that a proband is a gene carrier, whereas the empirical models evaluate the probability of identifying a mutation.

The main purpose of this study was to compare the performances of published models in predicting mutation test results in a large dataset. We collected pedigrees of probands investigated for BRCA1 and BRCA2 mutations in five clinical centres included in the Italian Consortium for Hereditary Breast and Ovarian Cancer. The combined sample included 568 families. Among those, 80 pathogenic mutations were identified in the BRCAl gene and 53 in the BRCA2 gene. Eight models were investigated: the University of Pennsylvania (Penn) model, the Myriad-1 model, the Myriad Tables, the Spanish model, the Finnish model, the Yale model, the Brcapro model, ${ }^{8-17}$ and a novel model that we refer to as the Italian Consortium (IC) model, intended to be used as a research tool. The latter is based on the parameter values of Brcapro (with minor modifications) and is implemented in the Mlink program of the Fastlink package. ${ }^{18}$

Mutations of the two genes are associated with differences in familial presentations. BRCAl is mutated preferentially in families with breast and ovarian cancer and more rarely is mutated in families with male breast cancer. ${ }^{19-21}$ BRCA2 was mapped primarily through families with male breast cancer. ${ }^{22}$

\section{Key points}

- Performances of eight models for predicting mutations were evaluated in 568 families screened for BRCA 1 and BRCA2 mutations and stratified by risk level and by clustering of cancer type

- Each model showed its own performance deficits, often underestimating the likelihood of a mutation in some types of families, while overestimating it for others

- All models underestimated mutation probability in the low risk $(<10 \%)$ group and most underestimated it for the moderate risk group (10-40\%). In contrast, all models except the Myriad Tables overestimated mutation probabilities in the highest risk group

- Overall, two of the Mendelian models (Brcapro and a novel model developed for this study) performed better than the others

- Models that evaluated probabilities separately for each gene (Mendelian models only) attributed an excess of families to BRCA1 compared with BRCA2; this effect was more pronounced for families with hereditary breast cancer

- This paper shows prospects for substantial improvement of performance, which could be achieved by adjusting the values of the relevant genetic parameters (allele frequencies and cancer penetrances in carriers and non-carriers)

Risk of breast cancer is higher for carriers of BRCAl mutations at younger ages $(<45$ years $)$, although this may not be the case at older ages. ${ }^{23}$ This shows that sufficient information may exist to assign specific mutation probabilities to each of the two genes. ${ }^{24}$ In contrast, the models developed so far calculate joint probability of mutation, with the notable exception of the Brcapro and IC models. Brcapro's authors suggest, however, that its ability to discriminate between genes is limited. ${ }^{25}$ In the last section of this paper, we address this problem by contrasting the probabilities calculated with the Brcapro and IC models with actual results of mutation tests, separately by gene and by family profile.

Previous validation studies considered one or two methods only or compared several methods without contrasting predictions with genetic test results. ${ }^{25-27}$ A recent analysis compared performances of several models, although Mendelian models were not considered. ${ }^{28}$ Our study is the first comprehensive attempt to evaluate model performances in a large series of families stratified according to family history and to consider the two genes separately. 


\section{PATIENTS AND METHODS Data collection}

Five cancer genetic clinics provided complete series of families screened for mutations in BRCAl and BRCA2. Because the clinics used different screening strategies, 458 families were screened for both genes, 104 for BRCAI only, and eight for BRCA2 only. In mutation analysis, three centres used direct automatic sequencing and a combination of protein truncation test (PTT) plus single strand conformational polymorphism (SSCP), one used PTT-SSCP and fluorescence-assisted mutational analysis (FAMA), and one used PTT-SSCP only. Pedigree data included information about breast and ovarian cancer of the first degree and second degree relatives of probands. Information on family history was reported to genetic counsellors by family members. Errors in reporting are possible, particularly for second degree relatives, ${ }^{29}$ but these errors also are likely to occur in the practical use of predictive models. ${ }^{25}$ Eligibility criteria varied across centres, but families with multiple cases of breast and ovarian cancer or cases of early onset cancer were selected preferentially. The resulting sample consisted of 570 families; two families were of Ashkenazi ancestry (one harboured a BRCA2 mutation) and were excluded from analysis. Among the 568 families that were included in this study, 151 had breast cancer and ovarian cancer in a single individual or in different relatives (HBOC), 357 had patients with breast cancer only (HBC), 31 had patients with ovarian cancer only (HOC), and 29 had at least one case of male breast cancer (MBC). Most of the probands (97\%) were affected by breast or ovarian cancer, or both.

\section{Empirical models}

The Penn model was the first predictive tool developed after the cloning of the BRCAl gene. ${ }^{8}$ It is based on logistic regression results of $B R C A 1$ testing on five variables that represent different family histories; tables that reported probabilities of mutation detection for 28 family groups were published (different tables were produced for Ashkenazi and non-Ashkenazi families). This model is applicable to the $B R C A l$ gene only, and it does not deal with families in which ovarian cancer only is present (HOC families). The Myriad-1 model is also a logistic regression model, in which 10 variables pertaining to age, ethnicity, and family history of cancer were included. ${ }^{9}$ This model also was built on BRCAl data only. Two other logistic regression models were published recently and predict probabilities of mutation detection in either BRCAl or $B R C A 2$; we refer to them in this paper as the Spanish model and the Finnish model. ${ }^{11}{ }^{12}$ Neither model can be applied to HOC families. Finally, the Myriad mutation prevalence tables display the proportion of probands, stratified in 42 possible groups, with identified mutations in BRCAl or BRCA2 in the analyses performed at Myriad; we used the August 2002 update, which included more than 10000 tests (http:// www.myriadtests.com). ${ }^{10} 30$

\section{Mendelian models}

The Yale model was developed before the cloning of the $B R C A l$ gene; it originated the Claus model for predicting risk of breast cancer. ${ }^{14}{ }^{15}$ On the basis of segregation analysis, the maximum likelihood model assumed a dominant gene with population frequency of 0.0033 and mean ages of onset of breast cancer in gene carriers and non-carriers of 55.4 (SD 15.4) years and 69.0 (15.4) years, respectively. ${ }^{13}$ Brcapro is another Mendelian model that is distributed as a part of the Mendelian counselling package CaGene ${ }^{17} 25$; it incorporates mutated allele frequencies and cancer specific penetrances derived from published results and uses Bayesian updating methods to compute carrier probabilities in pedigrees. Population frequencies of mutated BRCAl and
BRCA2 alleles are 0.0006 and 0.00022 , respectively. Penetrance files are updated regularly; in our study, we used the version available in August 2002. The Brcapro software was also used to evaluate the Yale model by replacing default penetrances with the above values. The last model investigated, the IC model, was developed specifically for this study. In this, five age groups were defined for each of five mutually exclusive phenotypes of women, and two liability classes were defined for men (with and without breast cancer, respectively), which led to a total of 27 liability classes. Incidence ratios between $B R C A 1$ and $B R C A 2$ carriers and noncarriers in each class were the mean values of the corresponding ratios in the Brcapro parameter file and were set prior to data analysis. The main difference between the Brcapro and IC models is with respect to calculation of penetrances for patients with multiple tumours (the Brcapro model multiplies probabilities of each cancer, whereas the IC model assigns specific liability classes to patients with bilateral breast cancer or breast cancer plus ovarian cancer).

\section{Sensitivity of molecular techniques}

Importantly, empirical models evaluate the probability of finding a mutation in a proband, whereas Mendelian models evaluate the probability that the proband is a gene carrier. If the sensitivity of the molecular techniques was $100 \%$, the two values would be directly comparable across different models. As a proportion of true gene carriers yield negative tests, however, the results of Mendelian models must be converted, as described below, before any comparison can be carried out. A direct estimate of sensitivity can be obtained by examining the proportion of families negative in a test that were linked to either locus: with this approach, Ford et al. found a value of $64 \%$; on the basis of their results, a more recent work assumed a sensitivity of $70 \% .^{231}$ Molecular techniques used to detect mutations varied across contributing centres and over time within centres; however, the most frequently used technique was PTT-SSCP, for which a blinded test showed sensitivity of $72-76 \%$ for abnormal migration detection and $60-65 \%$ for sequence analysis confirmation. $^{32}$ We therefore assumed a sensitivity value of $70 \%$ and converted the probability values calculated by Mendelian models by this factor. In addition, we explored the effect of changing the above assumption by recalculating mutation detection probabilities by using sensitivities of $60 \%$ and $80 \%$. We refer to this probability as the "mutation detection probability."

\section{Data analysis}

Mutation detection probabilities were computed in each family, and three analyses were performed for each model: comparison of observed and expected number of mutations, computation of the likelihood of the observed test results given the calculated probabilities, and receiver operating characteristic curve analysis.

Expected number of mutations was calculated by summing mutation detection probabilities over all families or over given subsets of families in a stratified analysis; these values were compared with the observed number of mutations by the $\chi^{2}$ test to evaluate calibration. ${ }^{33}$ In addition, we computed the Cox and Snell $U_{0}$ and $U_{1}$ test statistics, ${ }^{34}$ and we transformed them into the standardised $\mathrm{z}$ distribution to obtain appropriate confidence limits. The first index examines whether the predicted probabilities are systematically too high or too low (and is analogous to the $\chi^{2}$ test above), and the second index examines whether the distributions of individual assigned probabilities are too variable within families with the same risk. 
Table 1 Distribution of families by proband age and cancer type

\begin{tabular}{|c|c|c|c|c|c|c|c|c|c|c|c|}
\hline \multicolumn{4}{|c|}{ Pedigree characteristics } & \multicolumn{6}{|c|}{ Family history of cancer } & \multicolumn{2}{|c|}{ Mutation found } \\
\hline \multicolumn{2}{|l|}{ Proband } & \multirow{2}{*}{$\begin{array}{l}\text { Number } \\
\text { of families }\end{array}$} & \multirow{2}{*}{$\begin{array}{l}\text { Number } \\
\text { of relatives }\end{array}$} & \multirow{2}{*}{ s Breast } & \multirow[b]{2}{*}{ Ovarian } & \multirow{2}{*}{$\begin{array}{l}\text { Bilateral } \\
\text { breast }\end{array}$} & \multirow{2}{*}{$\begin{array}{l}\text { Breast and } \\
\text { ovarian }\end{array}$} & \multirow{2}{*}{$\begin{array}{l}\text { Male breast } \\
\text { cancer }\end{array}$} & \multirow{2}{*}{$\begin{array}{l}\text { Mean affected } \\
\text { members* }\end{array}$} & \multirow[b]{2}{*}{ BRCAI } & \multirow[b]{2}{*}{ BRCA2 } \\
\hline Cancer & Age (years) & & & & & & & & & & \\
\hline \multirow[t]{3}{*}{ Breast } & $<40$ & 132 & 1351 & 129 & 17 & 17 & 10 & 5 & 2.35 & 26 & 12 \\
\hline & $40-55$ & 143 & 1998 & 241 & 19 & 25 & 5 & 7 & 3.08 & 6 & 12 \\
\hline & $>55$ & 64 & 1010 & 127 & 9 & 13 & 3 & 2 & 3.41 & 4 & 5 \\
\hline Bilateral breast & & 71 & 890 & 90 & 7 & 20 & 2 & 0 & 2.68 & 6 & 10 \\
\hline \multirow{2}{*}{ Ovary } & $<50$ & 40 & 469 & 28 & 31 & 1 & 3 & 0 & 2.58 & 14 & 0 \\
\hline & $\geqslant 50$ & 39 & 582 & 45 & 24 & 3 & 2 & 1 & 2.92 & 11 & 5 \\
\hline Breast and ovarian & & 49 & 609 & 38 & 10 & 3 & 1 & 1 & 2.08 & 12 & 4 \\
\hline Male breast & & 15 & 241 & 27 & 3 & 1 & 0 & 0 & 3.07 & 0 & 5 \\
\hline Unaffected & & 15 & 134 & 24 & 2 & 3 & 1 & 0 & 2.00 & 1 & 0 \\
\hline Total & & 568 & 7284 & 749 & 122 & 86 & 27 & 16 & 2.68 & 80 & 53 \\
\hline
\end{tabular}

*Average number of members per family (probands included) affected by one or more breast or ovarian cancers.

\section{Log likelihood}

The logarithm of the likelihood of a set of mutation testing results was defined as $\ln (\mathrm{L})=\Sigma_{\mathrm{i}}$ a $\ln \left(\mathrm{p}_{\mathrm{i}}\right)+\mathrm{b} \ln \left(l-\mathrm{p}_{\mathrm{i}}\right)$, where $\mathrm{p}_{\mathrm{i}}$ is the mutation detection probability for family $i$, $a$ is $l$ if a mutation has been detected in the family and 0 otherwise, and $\mathrm{b}$ is $\mathrm{l}$ if no mutation has been detected and 0 otherwise. In computing probabilities separately for BRCA1 and BRCA2 (Brcapro and IC only), the likelihood function was modified accordingly, that is $\ln (\mathrm{L})=\Sigma \mathrm{a} * \ln \left(\mathrm{p}_{\mathrm{i} 1}\right)+\mathrm{b}^{*} \ln \left(\mathrm{p}_{\mathrm{i} 2}\right)+\mathrm{c}^{*} \ln \left(\mathrm{l}-\mathrm{p}_{\mathrm{i} 1}-\right.$ $\left.\mathrm{p}_{\mathrm{i} 2}\right)$, where $\mathrm{p}_{\mathrm{i} 1}$ and $\mathrm{p}_{\mathrm{i} 2}$ are mutation detection probabilities for $B R C A 1$ and $B R C A 2$, respectively, and $\mathrm{a}, \mathrm{b}$, and $\mathrm{c}$ are binary variables ( $\mathrm{a}$ is $\mathrm{l}$ only when a BRCAl mutation is detected, $\mathrm{b}$ is 1 only when a BRCA2 mutation has been detected, and c is 1 only when no mutations have been detected). This assumes that the probability of testing positive for both genes is negligible. Log likelihood differences between pairs of models were tested by bootstrapping and by the paired sign test. In bootstraps, 10000 samples were generated for each pairwise comparison, and the resulting series of values, each being a difference in total log likelihood, was ordered to obtain appropriate confidence intervals. The sign test was used to check that the median of the differences between individual likelihoods computed by any two models was different from zero.

\section{Receiver operating characteristic curves}

Receiver operating characteristic curves are used often in diagnostic test evaluations to determine the cut off value that provides the best discrimination between normal and abnormal patients. Receiver operating characteristic curve analysis was previously applied in validation studies of the Brcapro model ${ }^{26}{ }^{35}$ here, we applied this analysis to compare the performance of the eight models. Receiver operating characteristic curve analysis is based on sensitivity and specificity of each particular predictive model; therefore, the definition of sensitivity is different from that used for molecular techniques (above). In this case, sensitivity represents the fraction of participants with mutations with detection probability higher than a given value, and specificity is the fraction of participants without mutations with probability lower than that value. Receiver operating characteristic curves are constructed by plotting sensitivity against ( 1 -specificity) for all possible values of the mutation detection probability; the area under the receiver operating characteristic curve is the fraction of all probands with identified mutations that have detection probabilities higher than probands with no mutation. An important threshold value for sensitivity is $10 \%$; this is the probability threshold above which a person being counselled often is considered eligible for genetic testing. ${ }^{26}{ }^{36}$

\section{RESULTS}

\section{Sample characteristics}

Our sample included 568 families of Caucasian ancestry. The total number of relatives was 7284, $1000(13.7 \%)$ of whom were affected by breast cancer or ovarian cancer, or both. Cancers in probands were distributed as follows: $60 \%$ unilateral breast, $14 \%$ ovarian only, $13 \%$ bilateral breast, $9 \%$ breast and ovarian, and 3\% male breast; $3 \%$ of the probands were unaffected. The total number of mutations identified was 133: 80 in BRCA1 and 53 in BRCA2. Table 1 shows summary statistics of family histories of breast and ovarian cancer, as well as the number of identified mutations stratified by proband's cancer and age. Results indicate that the probability of finding mutations in BRCAl rather than in $B R C A 2$ (last two columns) varied among different groups of families. The ratio of BRCA1 to BRCA2 was larger than 1 in probands aged $<40$ years with breast cancer (row 1) but lower than 1 in probands aged $>40$ years (rows 2 and 3 ) (26:12 $v$ 10:17; odds ratio 3.7 (95\% confidence interval 1.3-10.4)). Similarly, BRCA2 mutations were only found in probands with ovarian cancer when they were aged $>50$ years. Presence of familial correlations for the type of cancer was also apparent: for example, prevalence of ovarian cancer was higher among relatives of probands with ovarian cancer than among relatives of all other probands. In addition, the proportion of BRCAI and BRCA2 mutations varied by family profile.

\section{Comparative performance of the eight models}

The subset of the total sample that could be analysed by all models consisted of 428 families (only families screened for both genes were taken into account, and 30 HOC families were excluded). The total number of identified mutations was 54 in BRCAl and 51 in BRCA2. Penn and Myriad-1 models were developed before the discovery of the $B R C A 2$ gene and considered mutation data in the BRCAl gene only; therefore, only mutations identified in this gene $(N=54)$ were counted as positive observations. Thus, results from the first two models could not be compared directly with results from the others. For the other six models, a positive observation was defined as the occurrence of a mutation in either gene $(N=105)$. Table 2 shows an overall evaluation of the predictions by all eight models. The first section (columns $2-4)$ shows the observed and expected statistics in the total sample; the second section shows the Cox and Snell $U_{0}$ and $\mathrm{U}_{1} \mathrm{z}$ transforms (columns 5 and 6), the third section (column 7) shows total log likelihoods, and the last section (columns 8-10) shows three statistics from the receiver operating characteristic curve analysis, namely the area under the curve (AUC) and the values of sensitivity and specificity in the 
Table 2 Predictions of the eight models evaluated by several statistics

\begin{tabular}{|c|c|c|c|c|c|c|c|c|c|}
\hline \multirow[b]{2}{*}{ Model } & \multicolumn{2}{|c|}{ Number of mutations } & \multirow[b]{2}{*}{$\chi^{2}$} & \multicolumn{2}{|c|}{ z transform } & \multirow{2}{*}{$\begin{array}{l}\text { Total log } \\
\text { likelihood }\end{array}$} & \multirow{2}{*}{$\begin{array}{l}\text { Sensitivity } \\
\text { (\%) }\end{array}$} & \multirow[b]{2}{*}{ Specificity (\%) } & \multirow[b]{2}{*}{ AUC } \\
\hline & Observed & Expected & & $\mathrm{U}_{0}$ & $U_{1}$ & & & & \\
\hline Penn & 54 & 64.7 & 1.7 & -1.73 & -1.49 & -144.5 & 74 & 69 & 0.787 \\
\hline Myriad-1 & 54 & 60.0 & 0.5 & -0.94 & -0.54 & -143.2 & 81 & 61 & 0.778 \\
\hline Myriad Tables & 105 & 82.0 & 8.0 & 3.07 & -3.53 & -218.5 & 78 & 50 & 0.717 \\
\hline Spanish & 105 & 97.9 & 0.7 & 0.95 & -4.75 & -240.0 & 80 & 35 & 0.651 \\
\hline Finnish & 105 & 79.2 & 10.3 & 3.98 & -9.66 & -247.7 & 70 & 62 & 0.72 \\
\hline Yale & 105 & 98.2 & 0.6 & 0.96 & -17.06 & -320.1 & 67 & 50 & 0.61 \\
\hline Brcapro & 105 & 100.0 & 0.3 & 0.70 & -7.42 & -226.7 & 80 & 56 & 0.757 \\
\hline IC & 105 & 109.0 & 0.2 & -0.54 & -4.57 & -213.6 & 84 & 51 & 0.768 \\
\hline
\end{tabular}

particular case when the threshold value of mutation detection probability was set to $10 \%$.

Overall performances of Penn and Myriad-1 models were similar; both slightly overestimated the probability of detecting mutations, their total log likelihoods were close, and their AUCs were almost identical. When the number of expected mutations was considered, the Myriad Tables and Finnish models performed worst, underestimating the overall detection probability (predicting $78 \%$ and $75 \%$ of the number of mutations actually found, respectively). The remaining four models showed a better agreement between observed and expected values, but they differed in their total likelihoods, probably indicating error compensation between different family strata. This hypothesis was supported by the value of the second Cox and Snell index (column 6), which showed highly significant values for all models but the Penn and Myriad-1 models.

When the total log likelihood was considered, the IC model attained the maximum value, followed by the Myriad Tables and the Brcapro model; the others (Spanish, Finnish, and Yale) were distant. Bootstrap tests showed that the difference between the IC model and Myriad Tables was not significant, whereas all other comparisons were below the significance level of 0.05 . On the other hand, the sign test was significant for the IC and Myriad model comparison, as well as all other cases. The receiver operator characteristic curve analysis (fig 1) also showed some differences among models. The Brcapro and IC models ranked first (AUC 76\% and77\%), although the difference between those and the Myriad Tables and Finnish model was small (AUC 72\%); the Spanish and Yale models performed worst (61\% and $65 \%)$.

Performances of the Mendelian models assumed a value of $70 \%$ for the sensitivity of molecular techniques. To explore the consequences of modifying this value, we recalculated observed and expected $\chi^{2}$ and total log likelihoods for the Brcapro and IC models with sensitivities of $60 \%$ and $80 \%$. Resulting $\chi^{2}$ values were higher in both cases for both models and $\log$ likelihoods also indicated a poorer fit (they were lower by about $5 \log$ units with sensitivity $80 \%$ ); an exception was the IC model when a sensitivity of $60 \%$ was used, in which case a small log likelihood increase was observed (0.58 log units).

Table 3 shows the log likelihoods stratified by proband's type of cancer and age (as in table 1), for the six models that evaluated mutation probabilities in either gene. Prediction ability varied considerably among models across the various categories of families. The largest difference concerned probands aged $<40$ years with breast cancer, where the likelihood of the Myriad Tables was 8-10 units lower than that of the two Mendelian models; this was apparently caused by a large underestimation of mutation detection probability by this model compared with the other two (17.2 $v 22.5$ and 23.3 predicted when 29 mutations were observed). On the other hand, the Myriad Tables performed better than the Mendelian models in families of probands aged $>55$ years with breast cancer and in those with bilateral breast cancer. In this category, the Mendelian models predicted a twofold excess of mutations (24.5 and 22.9 expected mutations in the Brcapro and the IC models, respectively, compared with 8.8 in the Myriad Tables with 14 observed mutations). Another important outcome concerned the families of probands aged $>50$ years with ovarian cancer, for which the two Mendelian models gave likelihoods that differed by about $6 \log$ units.

To further investigate differences in performances, families were stratified separately by risk in three groups $(<10 \%$, $10-40 \%$, and $>40 \%$ ) for each model (table 4 ). The proportion of families with probabilities $<10 \%$ varied among models from $31 \%$ in the Spanish model to $54 \%$ in the Finnish model. All models underestimated detection probability in the $<10 \%$ risk group; the largest discrepancy was observed for the Yale model (35 observed mutations $v 5.5$ expected) and the smallest for the Myriad Tables (23 v 13.0). In the intermediate risk group (10-40\%), a general excess of identified mutations was also observed, although the three Mendelian models produced predictions close to actual observations. The proportion of families in the highest risk group was the most variable among models, ranging from $10 \%$ in the Myriad Tables to $30 \%$ in the IC model. With the exception of the Myriad Tables, which almost exactly predicted the correct number of mutations, all other models overestimated the detection probability.

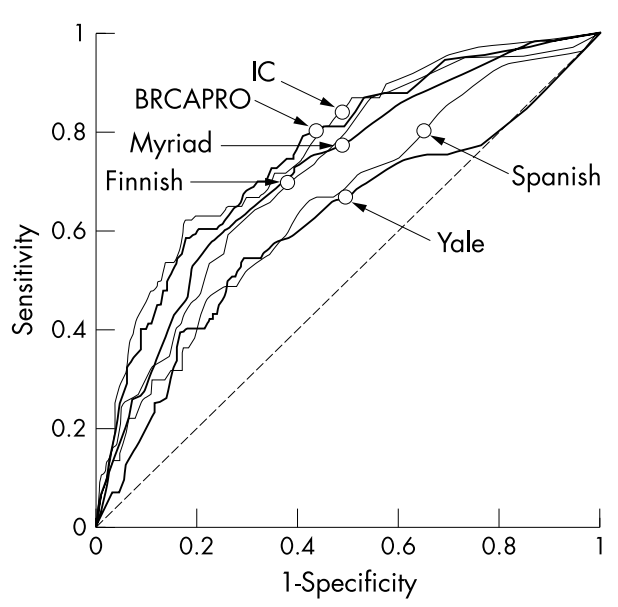

Figure 1 Receiving operator characteristic curves of six models that evaluated mutation detection probability in either BRCA1 or BRCA2. $\bigcirc$ value of sensitivity and specificity with threshold value of mutation detection probability set to $10 \%$. 
Table 3 Comparison of log likelihoods of six predictive model by probands' characteristics

\begin{tabular}{|c|c|c|c|c|c|c|c|c|c|}
\hline \multicolumn{4}{|c|}{ Pedigree characteristics } & \multicolumn{6}{|l|}{ Model } \\
\hline \multicolumn{2}{|l|}{ Proband } & \multirow[b]{2}{*}{ Number of families } & \multirow[b]{2}{*}{ Number of mutations } & \multirow[b]{2}{*}{ Myriad } & \multirow[b]{2}{*}{ Spanish } & \multirow[b]{2}{*}{ Finnish } & \multirow[b]{2}{*}{ Yale } & \multirow[b]{2}{*}{ Brcapro } & \multirow[b]{2}{*}{ IC } \\
\hline Cancer & Age (years) & & & & & & & & \\
\hline \multirow[t]{3}{*}{ Breast } & $<40$ & 94 & 29 & -60.1 & -60.0 & -60.9 & -54.6 & -51.8 & -50.7 \\
\hline & $40-55$ & 120 & 17 & -37.9 & -40.4 & -34.7 & -40.7 & -34.4 & -37.6 \\
\hline & $>55$ & 49 & 8 & -23.1 & -22.6 & -25.6 & -29.1 & -28.4 & -27.6 \\
\hline Bilateral breast & & 60 & 14 & -32.0 & -32.7 & -34.2 & -44.5 & -37.7 & -37.0 \\
\hline \multirow[t]{2}{*}{ Ovary } & $<50$ & 21 & 9 & -15.2 & -17.0 & -24.7 & -37.6 & -13.4 & -12.6 \\
\hline & $\geqslant 50$ & 23 & 11 & -21.5 & -28.3 & -31.5 & -53.8 & -28.4 & -22.2 \\
\hline Breast and ovarian & & 38 & 12 & -22.4 & -26.8 & -25.4 & -41.2 & -22.7 & -19.0 \\
\hline Male breast & & 9 & 4 & -3.7 & -7.7 & -8.8 & -10.5 & -6.1 & -4.3 \\
\hline Unaffected & & 14 & 1 & -2.6 & -4.4 & -1.8 & -8.1 & -3.8 & -2.7 \\
\hline Total & & 428 & 105 & -218.5 & -240.0 & -247.7 & -320.1 & -226.7 & -213.6 \\
\hline$\chi^{2}$ & & & & 25.29 & 22.73 & 28.66 & 260.78 & 26.45 & 16.93 \\
\hline
\end{tabular}

\section{Differentiating probabilities between BRCAI and BRCA2}

The Brcapro and IC models compute mutation probabilities separately for the two genes and cover all possible configurations of breast and ovarian cancers; this allowed us to examine their performances with respect to both genes in all the 568 families stratified by the four typical profiles (HBC, HOC, HBOC, and MBC). Table 5 shows the results of this analysis, in terms of $\chi^{2}$ and log likelihood statistics considering the two genes jointly and then separately by gene.

Total log likelihoods calculated over the 568 families were -381.7 for the IC model and -396.2 for Brcapro: with a difference of $14.5 \log$ units. Most of this difference (10.7 log units) was because of the HBOC profile, in which Brcapro predicted 41.1 mutations and the IC model 47.7 (57 were observed). This discrepancy was also responsible for most of the difference between total $\chi^{2}$ values $(4.2 v 14.8)$. When we examined the predictions separately by gene, we still found a difference of total likelihoods between the two models (7.1 $\log$ unit difference for BRCA1 and 6.3 for BRCA2, both in favour of the IC model). The most striking feature of this analysis, however, was the large excess of BRCAl mutations predicted by both models for the HBC group, with a corresponding large deficit of predicted BRCA2 mutations (about 48 mutations predicted by both models $v 27$ observed in BRCAI and about 12.5 predicted $v 33$ observed in BRCA2). For the other profiles, predictions were more accurate, although both models underestimated the number of mutations detected in BRCA2 for the HBOC profile (about six predicted $v 12$ observed).

\section{DISCUSSION}

Determination of the probability that a proband carries a $B R C A 1$ or $B R C A 2$ mutation by using family history is important and challenging. It requires weighing the possibility that a given cluster of cases among relatives is because of chance against the possibility of a predisposing gene. A simple approach-the "empirical approach" - involves collecting families tested for the genes, searching for variables that best discriminate between positive and negative families, and then building a model based on these. An alternative approach is to estimate the allele frequencies in the population and the cancer penetrances in both gene carriers and non-carriers and then applying a Mendelian model to each family (the Mendelian approach). A disadvantage of the empirical approach is that it needs large samples to provide reliable predictions; in addition, empirical models often refer to "number of cases per family" without clearly defining what a family is, which implies that this variable could mean

Table 4 Expected versus observed number of mutations by risk. ${ }^{*}$ Values are numbers (percentages)

\begin{tabular}{|c|c|c|c|c|c|}
\hline Model & Number of families & Observed & Expected & Observed/expected & $\chi^{2}$ \\
\hline \multicolumn{6}{|l|}{$\mathrm{P}<0.01$} \\
\hline Myriad Tables & $186(43)$ & 23 & 13.0 & 1.8 & 8.2 \\
\hline Spanish & $134(31)$ & 21 & 7.8 & 2.7 & 23.6 \\
\hline Finnish & $232(54)$ & 32 & 9.8 & 3.3 & 52.1 \\
\hline Yale & $198(46)$ & 35 & 5.5 & 6.4 & 162.6 \\
\hline Brcapro & $203(47)$ & 21 & 5.5 & 3.8 & 44.3 \\
\hline IC & $182(43)$ & 17 & 5.9 & 2.9 & 21.5 \\
\hline \multicolumn{6}{|l|}{$0.1<\mathrm{P}<0.4$} \\
\hline Myriad Tables & $200(47)$ & 60 & 46.4 & 1.3 & 5.2 \\
\hline Spanish & $213(50)$ & 51 & 45.8 & 1.1 & 0.7 \\
\hline Finnish & $133(31)$ & 42 & 28.2 & 1.5 & 8.6 \\
\hline Yale & 114 (27) & 26 & 23.9 & 1.1 & 0.2 \\
\hline Brcapro & 101 (24) & 22 & 21.9 & 1.0 & 0.0 \\
\hline IC & $116(27)$ & 22 & 26.1 & 0.8 & 0.8 \\
\hline \multicolumn{6}{|l|}{$P>0.4$} \\
\hline Myriad Tables & $42(10)$ & 22 & 22.6 & 1.0 & 0.0 \\
\hline Spanish & 81 (19) & 33 & 44.2 & 0.7 & 6.3 \\
\hline Finnish & 63 (15) & 31 & 41.1 & 0.8 & 7.2 \\
\hline Yale & $116(27)$ & 44 & 68.7 & 0.6 & 21.8 \\
\hline Brcapro & 124 (29) & 62 & 72.6 & 0.9 & 3.7 \\
\hline IC & $130(30)$ & 66 & 77.0 & 0.9 & 3.9 \\
\hline
\end{tabular}


Table 5 Comparison between the Brcapro and IC models in the entire dataset and by gene

\begin{tabular}{|c|c|c|c|c|c|c|c|c|}
\hline \multirow[b]{2}{*}{ Gene } & \multirow[b]{2}{*}{$\begin{array}{l}\text { Number of } \\
\text { families }\end{array}$} & \multirow[b]{2}{*}{$\begin{array}{l}\text { Number of } \\
\text { mutations }\end{array}$} & \multicolumn{3}{|l|}{ IC model } & \multicolumn{3}{|c|}{ Brcapro model } \\
\hline & & & $\begin{array}{l}\text { Mutations } \\
\text { expected }\end{array}$ & $\chi^{2}$ & Log likelihood & $\begin{array}{l}\text { Mutations } \\
\text { expected }\end{array}$ & $\chi^{2}$ & Log likelihood \\
\hline \multicolumn{9}{|c|}{$B R C A 1$ and $B R C A 2$} \\
\hline $\mathrm{HBC}$ & 357 & 60 & 62.7 & 0.14 & -204.2 & 59.3 & 0.01 & -204.8 \\
\hline $\mathrm{HBOC}$ & 151 & 57 & 47.7 & 2.63 & -138.8 & 41.2 & 8.31 & -149.5 \\
\hline $\mathrm{HOC}$ & 31 & 8 & 6.7 & 0.31 & -16.1 & 4.0 & 4.70 & -15.7 \\
\hline$M B C$ & 29 & 8 & 10.7 & 1.12 & -22.7 & 11.6 & 1.83 & -26.2 \\
\hline $\begin{array}{l}\text { Total } \\
\text { BRCA1 }\end{array}$ & 568 & 133 & 127.9 & 4.20 & -381.7 & 116.0 & 14.84 & -396.2 \\
\hline $\mathrm{HBC}$ & 357 & 27 & 49.0 & 11.4 & -97.2 & 47.4 & 10.1 & -94.3 \\
\hline $\mathrm{HBOC}$ & 151 & 45 & 41.2 & 0.5 & -102.7 & 35.8 & 3.1 & -110.4 \\
\hline $\mathrm{HOC}$ & 31 & 7 & 6.3 & 0.1 & -13.2 & 3.7 & 3.3 & -13.4 \\
\hline$M B C$ & 21 & 1 & 3.4 & 2.0 & -6.6 & 3.5 & 2.2 & -8.6 \\
\hline Total & 560 & 80 & 99.9 & 14.1 & -219.6 & 90.5 & 18.8 & -226.7 \\
\hline \multicolumn{9}{|l|}{ BRCA2 } \\
\hline $\mathrm{HBC}$ & 276 & 33 & 13.7 & 28.7 & -117.4 & 11.8 & 39.5 & -121.4 \\
\hline $\mathrm{HBOC}$ & 131 & 12 & 6.6 & 4.7 & -43.1 & 5.4 & 8.3 & -45.6 \\
\hline $\mathrm{HOC}$ & 28 & 1 & 0.4 & 1.1 & -3.9 & 0.3 & 2.0 & -2.9 \\
\hline$M B C$ & 29 & 7 & 5.8 & 0.3 & -18.1 & 5.9 & 0.2 & -19.0 \\
\hline Total & 464 & 53 & 26.4 & 34.8 & -182.5 & 23.5 & 50.0 & -188.9 \\
\hline
\end{tabular}

very different things in different families. A disadvantage of the Mendelian approach is that accurate estimates of penetrances and allele frequencies may be difficult to obtain; in addition, all existing empirical and Mendelian models currently assume that all mutant alleles at each gene have the same penetrance.

We compared relative performances of five empirical and three Mendelian models. We evaluated calibration of models with $\chi^{2}$ analysis, refinement of models with receiver operator characteristic curve analysis, and overall goodness of fit of models with log likelihood. Three of these eight models (Penn, Myriad-1, and Yale) were developed before the discovery of BRCA2 (Yale was proposed before the cloning of BRCAl) and were investigated here for completeness. Penn and Myriad-l could include observations on BRCAl only, and HOC families necessarily were excluded from analysis; within these limits, they performed relatively well, considering both the observed and expected $\chi^{2}$ statistics and the receiver operator characteristic curve analysis. The Yale model performed worse than all other models, although it must be acknowledged that the original analysis had the purpose of estimating the genetic parameters of a gene predisposing to breast cancer rather than predicting mutation risks. Among the other five models, Mendelian models provided higher resolution, as indicated by analysis of the receiver operator characteristic curve results. This is probably the consequence of calculating individualised probabilities-a major advantage of this approach compared with methods that tabulate probability values for a discrete number of familial groups. In addition, Mendelian models were more accurate for estimating the overall number of mutations. Considering log likelihood analysis, the Myriad Tables provided a value between those of the two Mendelian models.

A novel feature of our study is the analysis of predicted probabilities in the families stratified by probands' characteristics. Different approaches make different types of errors, so the possible similarity of results at the level of the total sample may be the consequence of error compensation in different family strata. For example, the Myriad Tables predicted little more than half of the observed mutations for families of probands aged $<40$ years with breast cancer compared with a better prediction by the Mendelian models, but this error was compensated for by the Myriad Tables' better prediction for families of probands aged $>55$ years with breast cancer and those with bilateral breast cancer.
Further analyses of this type may help to identify the categories of families for which adjustments of the parameter values that influence probability calculation are most needed.

Another interesting result concerned the number of observed and expected mutations in the families stratified by risk according to each model. All models underestimated the probability of detecting mutations in the families in the lowest risk class $(\leqslant 10 \%)$. The model performing best in this analysis was the Myriad Tables, but the predicted number of mutations was only about half the observed number. As the proportion of families included in this group was large for all models (about $45 \%$ on average), the number of "missed" mutations was large on an absolute scale. This result may have important consequences. On one hand, the number of actual mutations in low risk families may be higher than previously thought; on the other hand, the risk conferred by these mutations may be lower than anticipated. ${ }^{1237}$ This lack of fit may be specific to the Italian population, although data available so far about BRCA mutations in Italy does not suggest this. ${ }^{38}$ An alternative explanation would be penetrance heterogeneity among mutations; in this case, an excess of mutations that confer lower cancer risk would be identified in participants with relatively mild family histories.

Analysis of Mendelian models for accuracy in discriminating between the two genes showed an area of study in which further investigation could increase performance substantially. Our data confirmed the existence of different patterns of clinical expression between the two genes, as shown by the different BRCA1:BRCA2 mutation detection rate in different profiles. Both models predicted an overall excess of BRCAI mutations, and this excess was particularly large for HBC families (which were preferentially mutated in BRCA2); this suggests that current parameterisation of the models still is inadequate to attribute correct probabilities to each gene and that margins for improvement exist.

\section{Conclusion}

Whereas present Mendelian models perform generally better than empirical models (and in addition provide individualised probabilities that cover all possible familial configurations) adjustment of genetic parameters in two main areas could substantially improve their performance. These areas concern the families at low risk, who are likely to constitute a large fraction of future people being counselled and for whom the models underestimate the mutation detection 
probability, and the ability to discriminate between the two genes. Experience gained during our analysis suggests that a promising strategy is to re-estimate parameters from the data by maximum likelihood. As our data represent the genetic condition existing in Italy, this work may lead to a version of the Brcapro software customised for this country-an example that later could be extended to other populations.

\section{Authors' affiliations}

F Marroni, P Aretini, M A Caligo, G Cipollini, G Bevilacqua, Department of Oncology, Transplants and New Technologies in Medicine, Section of Pathology, University of Pisa, Pisa, Italy F Marroni, S Presciuttini, Center of Statistical Genetics, University of Pisa, Pisa, Italy

E D'Andrea, M Montagna, Department of Oncology and Surgical Sciences, Section of Oncology (E.D'A.); IST, Section of Viral and Molecular Oncology (M.M.); University of Padua, Padua, Italy L Cortesi, S Ferrari, Department of Oncology and Hematology (L.C); Department of Biomedical Science, Section of Biological Chemistry (S.F.); University of Modena and Reggio Emilia, Modena, Italy A Viel, M Santarosa, Experimental Oncology 1, Oncology Referral Center, IRCCS, Aviano (PN), Italy

E Ricevuto, R Bisegna, Department of Experimental Medicine, University of L'Aquila, L'Aquila, Italy

J E Bailey-Wilson, S Presciuttini, Inherited Disease Research Branch, National Human Genome Research Institute, National Institutes of Health, Baltimore, Maryland, USA

G Parmigiani, Departments of Oncology and Biostatistics, Johns Hopkins University, Baltimore, MD, USA

Correspondence to: Dr Presciuttini, Genetica Statistica, c/o Centro Retrovirus, SS Abetone e Brennero 2, 56127 Pisa, Italy; sprex@biomed.unipi.it

Conflicts of interest: None declared.

Funding: The Italian Consortium for Hereditary Breast and Ovarian Cancer is funded by the Italian Association for Cancer Research (AIRC). This work was in part supported by the National Research Council (CNR) and Italian Ministry of University and Research (MIUR).

Received 22 August 2003

Accepted for publication 16 October 2003

\section{REFERENCES}

1 Easton DF, Ford D, Bishop DT. Breast and ovarian cancer incidence in BRCA1mutation carriers. Breast Cancer Linkage Consortium. Am J Hum Genet 1995:56:265-71.

2 Ford D, Easton DF, Stratton M, Narod S, Goldgar D, Devilee P, Bishop DT, Weber B, Lenoir G, Chang-Claude J, Sobol H, Teare MD, Struewing J, Arason A, Scherneck S, Peto J, Rebbeck TR, Tonin P, Neuhausen S, Barkardottir R, Eyfjord J, Lynch H, Ponder BA, Gayther SA, ZeladaHedman M, and the Breast Cancer Linkage Consortium. Genetic heterogeneity and penetrance analysis of the BRCA1 and BRCA2 genes in breast cancer families. The Breast Cancer Linkage Consortium. Am J Hum Genet 1998;62:676-89.

3 Anglian Breast Cancer Study Group. Prevalence and penetrance of BRCA1 and BRCA2 mutations in a population-based series of breast cancer cases. Br J Cancer 2000;83:1301-8.

4 Bishop DT. BRCA1 and BRCA2 and breast cancer incidence: a review. Ann Oncol 1999;10(suppl 6):113-9.

5 Steel M, Smyth E, Vasen H, Eccles D, Evans G, Moller P, Hodgson S, StoppaLyonnet D, Chang-Claude J, Caligo M, Morrison P, Haites N. Ethical, social and economic issues in familial breast cancer: a compilation of views from the EC Biomed II Demonstration Project. Dis Markers 1999;15:125-31.

6 Edwards RT. Steering a course around the genetic iceberg. J Public Health Med 2001;23:3-4.

7 Parmigiani G. Modeling in medical decision making. A bayesian approach. New York: Wiley, 2002.

8 Couch FJ, DeShano ML, Blackwood MA, Calzone K, Stopfer J, Campeau L, Ganguly A, Rebbeck T, Weber BL. BRCAl mutations in women attending clinics that evaluate the risk of breast cancer. $N$ Engl J Med 1997;336: 1409-15

9 Shattuck-Eidens D, Oliphant A, McClure M, McBride C, Gupte J, Rubano T, Pruss D, Tavtiian S, Teng DHF, Adey N, Staebell M, Gumpper K, Lundstrom R, Hulick $M$, Kelly $M$, Holmen J, Lingenfelter $B$, Manley $S$, Fujumura $F$, Luce $M$, Ward B, Cannon-Albright L, Steele L, Offit K, Gilewski T, Norton L, Brown K, Schulz C, Hampel H, Schluger A, Giulotto E, Zoli W, Ravaioli A, Nevanlinna H, Pyrhonen S, Rowley P, Scalia J, Michaelson R, Scont R, Radice P, Pierotti M, Garber J, Isaacs C, Peshkin B, Lippman M, Dosik M, Caligo M, Greenstein R, Pilarski R, Weber B, Burgemeister R, Frank T,
Skolnick $M$, Thomas A. BRCA1 sequence analysis in women at high risk for susceptibility mutations. Risk factor analysis and implications for genetic testing. JAMA 1997;278:1242-50.

10 Frank TS, Deffenbaugh AM, Reid JE, Hulick M, Ward BE, Lingenfelter B, Gumpper KL, Scholl T, Tavtigian SV, Pruss DR, Critchfield GC. Clinical characteristics of individuals with germline mutations in BRCA1 and BRCA2: analysis of 10,000 individuals. J Clin Oncol 2002;20:1480-90.

11 de la Hoya M, Osorio A, Godino J, Sulleiro S, Tosar A, Perez-Segura P, Fernandez C, Rodriguez R, Diaz-Rubio E, Benitez J, Devilee P, Caldes T. Association between BRCA1 and BRCA2 mutations and cancer phenotype in Spanish breast/ovarian cancer families: implications for genetic testing. Int J Cancer 2002;97:466-71.

12 Vahteristo $\mathbf{P}$, Eerola $\mathrm{H}$, Tamminen A, Blomgvist $\mathrm{C}$, Nevanlinna H. A probability model for predicting BRCA1 and BRCA2 mutations in breast and breast-ovarian cancer families. Br J Cancer 2001;84:704-8.

13 Claus EB, Risch N, Thompson WD. Genetic analysis of breast cancer in the cancer and steroid hormone study. Am J Hum Genet 1991;48:232-42.

14 Claus EB, Risch N, Thompson WD. Autosomal dominant inheritance of earlyonset breast cancer. Implications for risk prediction. Cancer 1994;73:643-51.

15 Claus EB, Risch N, Thompson WD. The calculation of breast cancer risk for women with a first degree family history of ovarian cancer. Breast Cancer Res Treat 1993;28:115-20.

16 Berry DA, Parmigiani G, Sanchez J, Schildkraut J, Winer E. Probability of carrying a mutation of breast-ovarian cancer gene BRCAl based on family history. J Natl Cancer Inst 1997;89:227-38.

17 Parmigiani G, Berry D, Aguilar O. Determining carrier probabilities for breast cancer-susceptibility genes BRCA1 and BRCA2. Am J Hum Genet 1998:62:145-58.

18 Schaffer AA. Faster linkage analysis computations for pedigrees with loops or unused alleles. Hum Hered 1996;46:226-35.

19 Osorio A, Barroso A, Martinez B, Cebrian A, San Roman JM, Lobo F, Robledo M, Benitez J. Molecular analysis of the BRCA1 and BRCA2 genes in 32 breast and/or ovarian cancer Spanish families. Br J Cancer 2000;82:1266-70

20 Martin AM, Blackwood MA, Antin-Ozerkis D, Shih HA, Calzone K, Colligon TA, Seal S, Collins N, Stratton MR, Weber BL, Nathanson KL. Germline mutations in BRCA1 and BRCA2 in breast-ovarian families from a breast cancer risk evaluation clinic. J Clin Oncol 2001;19:2247-53.

21 Shih HA, Couch FJ, Nathanson KL, Blackwood MA, Rebbeck TR, Armstrong KA, Calzone K, Stopfer J, Seal S, Stratton MR, Weber BL. BRCAI and BRCA2 mutation frequency in women evaluated in a breast cancer risk evaluation clinic. J Clin Oncol 2002;20:994-9.

22 Wooster R, Neuhausen SL, Mangion J, Quirk Y, Ford D, Collins N, Nguyen K, Sea S, Tran T, Averill D, Fields P, Marshall G, Narod S, Lenoir GM, Lynch H, Feunteun J, Devilee P, Cornelisse CJ, Menko FH, Daly PA, Ormiston W, McManus R, Pye C, Lewis CM, Cannon Albright L, Peto J, Ponder BAJ, Skolnick MH, Easton DF, Goldgar DE, Stratton MR. Localization of a breast cancer susceptibility gene, BRCA2, to chromosome 13q12-13. Science 1994;265:2088-90.

23 Malone KE, Daling JR, Neal C, Suter NM, O'Brien C, Cushing-Haugen K, Jonasdottir TJ, Thompson JD, Ostrander EA. Frequency of BRCA1/BRCA2 mutations in a population-based sample of young breast carcinoma cases. Cancer 2000;88:1393-402.

24 Aretini P, D'Andrea E, Pasini B, Viel A, Costantini RM, Cortesi L, Ricevuto E, Agata S, Bisegna R, Boiocchi M, Caligo MA, Chieco-Bianchi L, Cipollini G, Crucianelli R, D'Amico C, Federico M, Ghimenti C, De Giacomi C, De Nicolo A, Della Puppa L, Ferrari S, Ficorella C, landolo D, Manoukian S, Marchetti P, Marroni F, Menin C, Montagna M, Ottini L, Pensotti V, Pierotti M, Radice P, Santarosa M, Silingardi V, Turchetti D, Bevilacqua G, Presciuttini S. Different expressivity of BRCA1 and BRCA2: analysis of 179 Italian pedigrees with identified mutation. Breast Cancer Res Treat 2003;81:71-9.

25 BRCAPRO validation, sensitivity of genetic testing of BRCA1/BRCA2, and prevalence of other breast cancer susceptibility genes. J Clin Oncol 2002;20:2701-12

26 Euhus DM, Smith KC, Robinson L, Stucky A, Olopade OI, Cummings S, Garber JE, Chittenden A, Mills GB, Rieger P, Esserman L, Crawford B, Hughes KS, Roche CA, Ganz PA, Seldon J, Fabian CJ, Klemp J, Tomlinson G. Pretest prediction of BRCA1 or BRCA2 mutation by risk counselors and the computer model BRCAPRO. J Natl Cancer Inst 2002;94:844-51.

27 Shannon KM, Lubratovich ML, Finkelstein DM, Smith BL, Powell SN, Seiden MV. Model-based predictions of BRCA1/2 mutation status in breast carcinoma patients treated at an academic medical center. Cancer 2002;94:305-13.

28 De la Hoya M, Diez O, Perez-Segura P, Godino J, Fernandez JM, Sanz J, Alonso $C$, Baiget $M$, Diaz-Rubio $E$, Caldes T. Pre-test prediction models of BRCA1 or BRCA2 mutation in breast/ovarian families attending familial cancer clinics. J Med Genet 2003;40:503-10

29 Love RR, Evans AM, Josten DM. The accuracy of patient reports of a family history of cancer. J Chronic Dis 1985;38:289-93.

30 Frank TS, Manley SA, Olopade OI, Cummings S, Garber JE, Bernhardt B, Antman K, Russo D, Wood ME, Mullineau L, Isaacs C, Peshkin B, Buys S, Venne V, Rowley PT, Loader S, Offit K, Hampel H, Brener D, Winer EP, Clark S, Weber B, Strong LC, Reiger P, McClure M, Ward B, ShattuckEidens D, Oliphant A, Skolnick MH, Thomas A. Sequence analysis of BRCA and BRCA2: correlation of mutations with family history and ovarian cancer risk. J Clin Oncol 1998;16:2417-25.

31 Basham VM, Lipscombe JM, Ward JM, Gayther SA, Ponder BA, Easton DF Pharoah PD. BRCA1 and BRCA2 mutations in a population-based study of male breast cancer. Breast Cancer Res 2002;4:R2. 
32 Eng C, Brody LC, Wagner TM, Devilee P, Vijg J, Szabo C, Tavtigian SV, Nathanson KL, Ostrander E, Frank TS. Interpreting epidemiological research: blinded comparison of methods used to estimate the prevalence of inherited mutations in BRCA1. J Med Genet 2001;38:824-33.

33 DeGroot MH FS. Assessing probability assessors: calibration and refinement. Statistical decision theory and related topics III 1982;1:291-314.

34 Cox DR, Snell EJ. Analysis of binary data. London, New York, Tokyo, Melbourne, Madras: Chapman and Hall, 1989:41-3.

35 Iversen E, Parmigiani G, Berry D. Validating Bayesian prediction models: a case study in genetic susceptibility to breast cancer. Case studies in Bayesian statistics 1998;IV:321-38.
36 American Society of Clinical Oncology. Policy statement: genetic testing for cancer susceptibility (approved February 20, 1996) Recommendations pertaining to clinical aspects of genetic testing for cancer susceptibility. Alexandria: ASCO, 2002

37 Ford D, Easton DF, Peto J. Estimates of the gene frequency of BRCA1 and its contribution to breast and ovarian cancer incidence. Am J Hum Genet 1995;57:1457-62.

38 Ottini L, D'Amico C, Noviello C, Lauro S, Lalle M, Fornarini G, Colantuoni OA, Pizzi C, Cortesi E, Carlini S, Guadagni F, Bianco AR, Frati L, Contegiacomo A, Mariani-Costantini R. BRCA1 and BRCA2 mutations in central and southern Italian patients. Breast Cancer Res 2000;2:307-10.

\section{$\mathrm{ECHO}$}

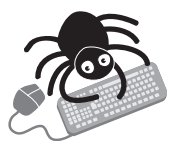

Please visit the Journal of Medical Genetics website [www. jmedgenet. com] for a link to the full text of this article.
Transforming growth factor- $\beta_{1}$ genotype and susceptibility to chronic obstructive pulmonary disease

L Wu, J Chau, R P Young, V Pokorny, G D Mills, R Hopkins, L McLean, P N Black

Background: Only a few long term smokers develop symptomatic chronic obstructive pulmonary disease (COPD) and this may be due, at least in part, to genetic susceptibility to the disease. Transforming growth factor $\beta_{1}\left(\right.$ TGF- $\left.\beta_{1}\right)$ has a number of actions that make it a candidate for a role in the pathogenesis of COPD. We have investigated a single nucleotide polymorphism at exon 1 nucleotide position $29(\mathrm{~T} \rightarrow \mathrm{C})$ of the TGF- $\beta_{1}$ gene that produces a substitution at codon 10 ( $\mathrm{Leu} \rightarrow$ Pro).

Methods: The frequency of this polymorphism was determined in 165 subjects with COPD, 140 healthy blood donors, and 76 smokers with normal lung function (resistant smokers) using the polymerase chain reaction and restriction enzyme fragment length polymorphism. Results: The distribution of genotypes was Leu-Leu (41.8\%), Leu-Pro (50.3\%), and Pro-Pro $(7.9 \%)$ for subjects with COPD, which was significantly different from the control subjects (blood donors: Leu-Leu (29.3\%), Leu-Pro (52.1\%) and Pro-Pro (18.6\%), p = 0.006; resistant smokers: Leu-Leu (28.9\%), Leu-Pro (51.3\%) and Pro-Pro (19.7\%), p =0.02). The Pro ${ }^{10}$ allele was less common in subjects with COPD (33\%) than in blood donors $(45 \%$; OR $=0.62,95 \%$ CI 0.45 to $0.86, \mathrm{p}=0.005)$ and resistant smokers $(45 \%$; OR $=0.59,95 \%$ CI 0.40 to 0.88 , $\mathrm{p}=0.01$ ).

Conclusions: The proline allele at codon 10 of the TGF- $\beta_{1}$ gene occurs more commonly in control subjects than in individuals with COPD. This allele is associated with increased production of TGF- $\beta_{1}$ which raises the possibility that TGF- $\beta_{1}$ has a protective role in COPD. A Thorax 2004;59:126-129. 